\title{
A CULTURA DO CONSUMO: UMA LEITURA PSICANALÍTICA LACANIANA
}

\author{
Vanessa Leite Teixeira \\ Luís Flávio Silva Couto
}

\begin{abstract}
RESUMO. O presente artigo pretende fazer uma leitura da cultura capitalista de consumo na contemporaneidade tomando como aporte a Teoria dos Discursos, desenvolvida por Jacques Lacan no seminário O Avesso da Psicanálise (1969-1970) e modificada na Conferência de Milão, proferida por ele em 12 de maio de 1972. O tema é abordado pela via do capitalismo, cujos desdobramentos levam ao consumo de produtos elevados à categoria de objetos-tampão da falta estrutural denominados latusas, de modo a estimular o excesso de gozo. A importância dessa leitura sustenta-se na atualidade do tema e nas consequências perigosas que podem advir ao sujeito quando do usufruto do gozo ilimitado acima das restrições fundadoras do desejo. Parte-se do pressuposto de que não há cura para a divisão subjetiva. Neste sentido, diante do engodo contemporâneo da completude o campo de impossibilidade de sutura do desejo é considerado o ponto de apoio para a clínica lacaniana.
\end{abstract}

Palavras-chave: Os discursos na psicanálise lacaniana; cultura do consumo; latusa.

\section{THE CULTURE OF CONSUMING: A LACANIAN PSYCHOANALYST READING}

\begin{abstract}
This article concerns a reading of the capitalist culture of contemporary consuming, based on the theory of the Discourses, developed by Jacques Lacan on the book XVII The Other Side of Psychoanalysis (1969-1970) and at the Conference in Milan, proffered by him on May 12, 1972. The issue is approached through the capitalism, of which the consequences are the consuming of industrial products elevated to the category of objects able to fill the structural flaw, called lathousas, to stimulate the excess of jouissance. The relevance of this issue refers to its topical aspect and its dangerous consequences which may appear to the subject, related to unlimited enjoyment over the restrictions which inaugurate the desire. The inexistence of a healing to the subject division is a premise. Thus, opposite to the contemporary misleading of completeness, the impossibility of mending de desire is considered the support to the lacanian clinic.
\end{abstract}

Key words: Discourses in lacanian psychoanalysis; culture of consuming; lathousa.

\section{LA CULTURA DEL CONSUMO: UNA LECTURA PSICOANALÍTICA LACANIANA}

RESUMEN. Este artículo hace una lectura de la cultura capitalista del consumo contemporáneo, fundada en la teoría de los discursos desarrollada por Jacques Lacan en El seminario, El revés de la psicoanálisis (1969-1970) y cambiada en la Conferencia de Milano, proferida en 12 de Mayo de 1972. El tema es abordado por la vía del capitalismo, cuyos desdoblamientos llevan al consumo de productos elevados a la categoría de objetos tampones de la falta estructural, llamados latusas, para estimular el exceso de gozo. La importancia de esta lectura está sostenida en su actualidad y en las peligrosas consecuencias que pueden advenir al sujeto debido a la superioridad del gozo ilimitado sobre las restricciones fundadoras del deseo. Es presunto que no hay cura para la división subjetiva. En ese sentido, frente al engodo contemporáneo de la integridad, la imposibilidad de sutura del deseo es considerada el punto de apoyo para la clínica lacaniana..

Palabras-clave: Los discursos en psicoanálisis lacaniana; cultura del consumo; latusa.

Diariamente somos inundados de propagandas que prometem o acesso à perfeição por meio de seus produtos. Carros são ofertados como o complemento do motorista; sapatos esportivos são oferecidos ao consumidor não para correr, pois correr ficou ultrapassado: é preciso voar. Um grande banco nacional se autodenomina completo e um cartão de crédito é dito capaz de fazer tudo e mais um pouco,

\footnotetext{
Psicóloga. Aluna de pós-graduação em Psicologia, nível Mestrado, pela Pontifícia Universidade Católica de Minas Gerais.

\# Psicólogo. Doutor em Filosofia. Professor Adjunto da Pontifícia Universidade Católica de Minas Gerais.
} 
até mesmo consertar o liquidificador que quebrou. Se o lugar dos consumidores é o shopping center, cabe questionar o lugar ocupado pelo sujeito na cultura contemporânea do consumo excessivo.

A psicanálise sustenta que a promessa de completude é uma propaganda enganosa. Desde que as relações sociais humanas são organizadas por intermédio da linguagem, o homem está dividido, incompleto, estruturalmente barrado de atingir a plenitude da satisfação. Todavia, parece restar-lhe uma nostalgia que busca recuperar uma integralidade que nunca se teve nem se terá. Essa procura pela completude, remanescente nos dias atuais, remete-nos ao ideal de unidade do ser, apontado em $O$ Banquete pela boca de Aristófanes (Platão, séc. IV a.C./1972).

Segundo esse mito, a natureza humana teria sido composta por três espécies de homens: o macho, a fêmea e o andrógino, caracterizado pela combinação dos dois primeiros. Seu corpo, de formas arredondadas, era dotado de força, agilidade e coragem, e seu andar era circular. Diz-se que um dia os andróginos empreenderam a escalada aos céus a fim de guerrear contra os deuses. Júpiter e os outros deuses decidiram punir tal insolência dividindo os andróginos em dois. Caso sua índole atrevida permanecesse, seriam novamente cindidos em dois. Consumado o castigo da separação, cada parte desejou unir-se à sua metade destacada, com o intuito de remediar a fragilidade humana através da busca pela recondução ao estado completo anterior:

\begin{abstract}
por conseguinte, desde que a nossa natureza se mutilou em duas, ansiava cada uma por sua própria metade e a ela se unia, e envolvendo-se com as mãos e enlaçando-se um no outro, no ardor de se confundirem, morriam de fome e de inércia em geral, por nada quererem fazer longe um do outro (Platão, 1972, 191a).
\end{abstract}

É dessa sensação nostálgica de completude que o sistema capitalista, agregado ao discurso científico, alimenta seu modo de produção e seu funcionamento, ou seja, por meio da rotatividade de produtos potencialmente descartáveis. Nisso configura-se a cultura do consumo.

Os modos de produção, como observa Marx (1857-1858/1989), são diferenciados em cada época e marcam o progresso da economia na sociedade. Segundo ele, a pré-história da civilização humana, orientada pela produção rural e artesanal, é superada pelas relações de produção burguesas a partir do século XVIII, com a Revolução Industrial. Nesse momento temos o surgimento da sociedade industrial, caracterizada pela atividade produtiva exterior ao quadro familiar, pela divisão técnica do trabalho, pela acumulação de capital e pela orientação para o crescimento econômico por meio da produção em larga escala. A partir dos argumentos de Marx, Masi (1999) destaca que os modos de produção e o progresso tecnológico marcam a peculiaridade da sociedade industrial, finda em meados do século XX.

Para Lacan (1969-1970/1992), essa organização societária refere-se ao discurso do capitalista articulado em semelhança ao discurso universitário que comporta um senhor que espolia do trabalhador o seu saber-fazer. Lacan ressalta que a Revolução não trouxe a melhoria da qualidade de vida como se pretendia, mas instaurou a ilusão de distribuição igualitária de gozo por meio do acesso aos produtos. Por conseguinte, no laço capitalista propriamente dito, reconhecemos o funcionamento de uma sociedade de consumo em que os trabalhadores tornam-se um material humano tão consumível quanto os produtos.

\section{O DISCURSO E O LAÇO SOCIAL}

Lacan (1969-1970/1992) também aponta que a linguagem possibilita a subsistência de certas relações estáveis no campo das trocas sociais. Neste sentido, é mediante a estrutura da linguagem que se torna possível estabelecer os laços sociais que permitem edificar a civilização. Todavia, conforme antecipado por Freud (1930/1996), viver em sociedade implica perder em liberdade para ganhar em segurança, uma vez que os grupos sociais são construídos graças às restrições impostas à satisfação pulsional sexual e agressiva. Tais limitações geram frustrações que dominam as relações sociais e, assim, em vez de sentir-se confortável em meio à civilização, o homem experiencia uma sensação de mal-estar.

É nesse sentido que, a partir do arcabouço da linguística, Lacan (1969-1970/1992) propõe que o significante introduz a barra à satisfação total, ou seja, o homem é incompleto porque fala. A estrutura de linguagem permite-lhe apenas aproximações daquilo que nomeia e isso configura a representação. Não se pode dizer tudo, uma vez que faltam palavras para fazê-lo. Assim, entrar na estrutura discursiva do simbólico implica em uma perda estrutural e, dessa maneira, o ser falante constitui-se como falta-a-ser.

Uma vez que a linguagem só pode tocar o real de modo a representá-lo, sobra um resto sem ser dito e a articulação significante se repete sem cessar nas tentativas malogradas de se dizer tudo. Essa repetição da cadeia significante consiste na resposta à perda de gozo, através da produção de uma espécie de entropia 
que funciona a partir de um suplemento de gozo denominado "objeto $a$ " na vertente do mais-de-gozar. A perda de gozo engendra a falta estrutural quando da entrada na linguagem. Como há uma defasagem entre a perda de gozo e o suplemento de gozo, a repetição se mantém.

Esse acesso ao Outro, lugar da linguagem, desnaturaliza o homem e modula suas necessidades instintivas. Segundo Lacan (1958/1998), a presença do significante tem o efeito de sujeitar as necessidades à demanda, a qual se refere a algo distinto daquilo por que ela clama. A demanda, para além do objeto em si, é sempre da presença ou da ausência do Outro, o qual é elevado à categoria de detentor da capacidade de suprir as necessidades já transformadas pela linguagem. Todavia, esse Outro não pode fornecer o que o demandante reclama, pois não é detentor da completude. Como é sempre frustrada, a demanda mantém-se insaciável e se repete. Tal repetição pode ser equiparada à repetição da cadeia significante em busca do suplemento de gozo. Dessa forma, pode-se cogitar que o discurso é uma demanda, um pedido de mais satisfação, funcionando como um aparelho de acesso ao gozo que, embora limitado, poderia ser possível.

Nessa tentativa de acesso a algum gozo, a organização social de cada época pretende articular os modos de lidar com essa perda estrutural de satisfação,

\section{Discurso do Mestre}

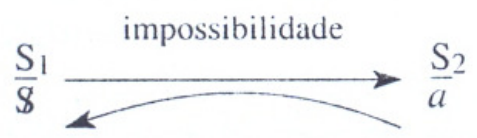

esclarecido por

regressão do:

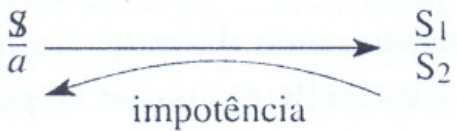

referente à entrada na linguagem. No sistema capitalista, os objetos da cultura são elevados à categoria desse suplemento de gozo representado pelo objeto $a$. Nesse sentido, o funcionamento do capitalismo é alimentado pelo poder de consumo desses objetos. A veiculação midiática de novos ideais relacionados a esse poder que se encontra ligado, por exemplo, à beleza, à riqueza e à sensualidade, atrai os sujeitos na procura da pretensa completude. Aproveitando-se dessa ilusão, o sistema capitalista, unido ao discurso científico, seduz o consumidor com objetos travestidos de suplementos de gozo, na medida em que são ofertados enquanto satisfação total e imediata.

\section{A ESTRUTURA DOS DISCURSOS}

As organizações civilizatórias são caracterizadas por Lacan (1969-1970/1992), em seu seminário $O$ Avesso da Psicanálise, por quatro tipos de articulação significante (Figura 1). Uma vez que o significante não apenas é conceituado como aquilo que "representa o sujeito ante outro significante" (Lacan, 19691970/1992, p.19), como é estruturado como uma linguagem, o discurso representa uma maneira de se usar a linguagem como vínculo social e como um modo de acesso ao gozo.

\section{Discurso da Universidade}

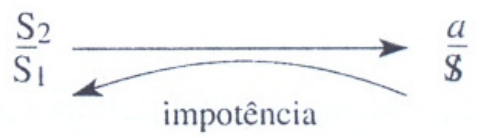

esclarecido por sua

"progressão" para o:

\section{Discurso do Analista}

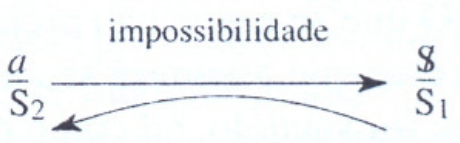

Fonte: Lacan (1970/2003, p. 447) em Radiofonia.

Os lugares são de:

$\frac{\text { o agente }}{\text { a verdade }} \frac{\text { o outro }}{\text { a produção }}$

Figura 1. Os Quatro Discursos Radicais 
Os discursos são articulações de quatro letras em quatro lugares definidos. Rabinovich (2001) orienta que o Agente é aquele que organiza o discurso, o Outro é a alteridade à qual se dirige cada discurso, a Produção refere-se ao lugar do produto engendrado pelo discurso, e a Verdade, mantida em disjunção com a Produção, é o posto que fundamenta o discurso.

As letras articuladas nesses lugares, mas em posições diferentes a cada discurso, são:

- $\mathrm{O} \mathrm{S}_{1}$, chamado de significante mestre, que intervém no campo definido da linguagem para representar alguma coisa;

- $\mathrm{O} \mathrm{S}_{2}$, nomeado como saber, responsável por ligar os significantes em uma relação de rede;

- $\mathrm{O} \$$, chamado sujeito barrado ou sujeito dividido;

- O objeto $a$, definido como um resto da operação de surgimento do sujeito na cadeia significante, sendo causa de desejo, quando representa aquilo que provoca o desejo, ou mais-de-gozar, quando é tomado como suplemento de gozo a ser recuperado na repetição da cadeia significante. $\mathrm{O}$ objeto $a$, enquanto o que resiste à apropriação significante, circula entre os significantes e escapa a toda captura. Ele remete à falta no campo simbólico ou no campo do Outro que impede a conexão entre a produção e a verdade. Com isso pode-se dizer que não é possível nem se consegue dizer toda a verdade. "Dizê-la toda é impossível, materialmente: faltam as palavras" (Lacan, 1974/1993, p.11), só sendo possível, então, meiodizê-la.

Os discursos radicais tais como formalizados por Lacan em Radiofonia (Lacan, 1970/2003, p. 447) são: O Discurso do Mestre, formalizado a partir da dialética hegeliana do senhor e do escravo, caracteriza a organização social da tradição, apontando a existência de um ordenador que escamoteia a sua castração para definir as relações sociais a partir da maestria;

- O Discurso da Histérica se caracteriza pela convocação de um mestre que produza um saber capaz de equacionar a falta do gozo pleno;

- O Discurso do Analista engendra a situação analítica a partir do lugar do outro ocupado pelo sujeito dividido e possibilita que o analisante produza um saber no lugar da verdade em vez de o analista oferecer-lhe soluções prontas;

- O Discurso Universitário, formalizado a partir da apropriação do saber do escravo em benefício do senhor, configura uma tirania do saber enquanto totalidade. Lacan (1969-1970/1992) considera que esta troca da posição do saber institui o senhor moderno, cuja estruturação social se organiza pela burocracia.

É possível notar que a estruturação dos discursos denominados discursos radicais representa a impossibilidade de abarcar a totalidade por meio da linguagem. Há uma disjunção entre os lugares da Produção e da Verdade, o que implica na impossibilidade de se produzir uma verdade por meio da articulação significante. Isso corrobora a ideia de que abarcar a realidade por meio da função mediadora da linguagem comporta a falta. Uma vez que a psicanálise de orientação lacaniana pressupõe que os discursos carregam a incurabilidade da falta estrutural, cabe questionar de que modo o sistema capitalista se aproveita disso em seu discurso.

\section{O DISCUSO DO CAPITALISTA}

Em uma lição de O Seminário 17, Lacan (19691970/1992) inicialmente faz equivaler o discurso universitário ao discurso capitalista, cujo surgimento se dá em conexão com o desenvolvimento da ciência. Marx, um dos críticos do capitalismo, produz uma teoria científica sobre o capital e as relações trabalhistas, nomeando o excedente da produção como mais-valia. Segundo Lacan, Marx, na tentativa de revolucionar esse sistema pela proposta socialista, acaba por repetir o discurso de maestria e, com isso, formaliza a mola propulsora do capitalismo.

Na lição referida acima, o deslizamento discursivo do discurso do mestre em direção ao discurso do capitalista coloca no lugar de agente o saber espoliado do escravo, o qual é reduzido a unidade de valor e, "passando um estágio acima, o mais-de-gozar não é mais-de-gozar, ele se inscreve simplesmente como valor a registrar ou deduzir da totalidade do que se acumula" (Lacan, 1969-1970/1992, p.84). Por ter sido quantificada, a mais-valia adquire o estatuto de espoliação do gozo do escravo pelo capitalista, podendo ser acumulada e utilizada na lógica econômica de investimento no próprio sistema para produção de maior lucro. Lacan (1969-1970/1992) sustenta que o sentido da sociedade de consumo se dá quando o humano é qualificado por um mais-de-gozar qualquer, sendo, assim, equiparado a um produto forjado pela indústria. $\mathrm{O}$ proletariado torna-se material humano produtor dessa sociedade e é impulsionado pelo mandamento de trabalhar mais para produzir mais. Como os produtos não possuem estatuto de completude, deve-se continuar a produção. 
Acompanhando Lacan, Alvarez (2008) também faz equivaler o discurso do capitalista ao discurso universitário, denominando-o de capitalismo científico. Seu desenvolvimento é caracterizado por uma sofisticação do discurso do mestre, graças à sua união com a ciência. É o mandato científico de seguir sabendo, representado pelo $S_{1}$, que comanda o saber no lugar de agente e o torna incessante. $\mathrm{O}$ mestre antigo é pervertido por um mestre do saber sustentado pelo encobrimento da verdade, o que caracteriza a sociedade capitalista. No lugar do outro, encontra-se, no discurso do mestre, aquele que sempre trabalha, e no discurso da ciência, o $a$ estudante, como diz Lacan (1969-1970/1992). O lugar que o $a$ estudante ocupa no discurso universitário, ali enquanto discurso da ciência, configura sua equivalência aos objetos de gozo da sociedade capitalista, representados pelo objeto $a$.

Enquanto os trabalhadores ou os astudados (Alvarez, 2008) trabalham para o saber, o sistema capitalista goza de sua posição de objetos a serem consumidos e a consumirem a si mesmos à exaustão. O próprio sujeito localiza-se no lugar da produção do que Lacan, como veremos abaixo, chamou de latusas, tornando-se produto tão consumível quanto os produtos industrializados.

Em 12 de maio de 1972, em Milão, Lacan (1972) proferiu uma conferência na qual o discurso do capitalista sofre modificações. Souza (2003) ressalta que esse novo discurso rompe com a lógica dos quatro discursos radicais, tal como trabalhada no seminário $O$ Avesso da Psicanálise. Na sua nova formulação, o discurso do capitalista, além de possibilitar uma circularidade completa no circuito dos postos, na qual todos os vértices podem ser alcançados, sofre uma comutação dos significantes que ocupam os lugares de agente e da verdade, a partir do discurso do mestre (Figura 2).

\section{Discurso do Mestre}
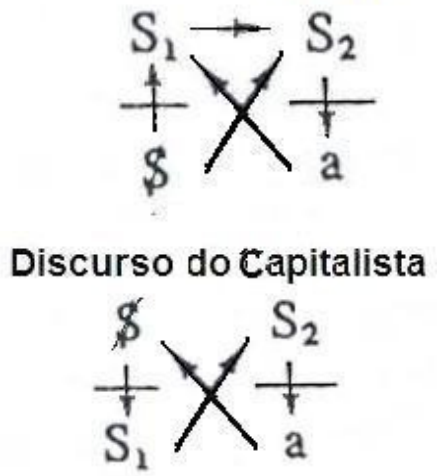

Figura 2. O Discurso do Capitalista
Lacan (1972) aponta que o discurso capitalista é dotado de um ritmo muito rápido e é utilitário do saber científico para produzir objetos a serem consumidos e destruídos, cujo funcionamento, a partir da mais-valia, produz objetos elevados à categoria do objeto $a$ na sua vertente do mais-de-gozar. Esse sistema cultural sustenta-se na crença de distribuição do gozo para todos e em partes iguais, por meio da apropriação dos produtos da cultura. Assim, a sociedade de mercado oferece ao sujeito objetos elevados à categoria daquilo que completaria a falta-a-ser.

Como consequência, no discurso capitalista o objeto $a$ perde sua característica de deslizamento e se apresenta como passível de acesso. Desde que o objeto não é de fato acessível, o sujeito se perde neste circuito enganoso, queixa-se de seu mal-estar e se aliena de sua verdade: a de que é dividido e limitado. Uma vez alienado, o sujeito aceita os ditames da cultura capitalista, acredita no poder de complementação dos objetos e entra no circuito do consumo excessivo, que torna a extração de gozo uma prorrogação incessante, indo e voltando em torno de um gozo perdido e ofertado como possível.

Isso se dá pela promoção da produção e da exploração de objetos elevados à categoria do objeto $a$, através de um cortejo à permissividade de gozo, independente das consequências. Nessa organização cultural, o sujeito é, então, incessantemente impelido a gozar por meio do consumo dos objetos da cultura e somente a morte é mantida como limitação ao gozo não castrado. Disso se conclui que o discurso capitalista refere-se a uma posição a partir da qual o sujeito consente com o rechaço da castração e faz existir o ídolo capitalista com a produção dos objetos $a$, denominados por Lacan (1969-1970/1992) de latusas.

\section{OS SULCOS DA ALETOSFERA E AS LATUSAS}

Lacan propõe o neologismo latusa no contexto de sua discussão sobre as tentativas do sujeito contemporâneo de se livrar das frustrações geradas pelo mal-estar da nossa civilização. Submetidos à estrutura discursiva simbólica e à perda estrutural, somos conduzidos pelo discurso do capitalista à ilusão da existência de objetos que, supostamente, seriam capazes de suprir a falta. Latusas é o nome que Lacan dá a esses suplementos de gozo ofertados pelo capitalismo enquanto promessa de satisfação plena suposta sutura da falta-a-ser.

Para esclarecer o que vem a ser a latusa, Lacan (1969-1970/1992) começa por apontar que a ciência é muito produtiva na sua tarefa de determinar o ente, 
isto é, aquilo que é enquanto o ser das coisas, sujeito real da apreensão no sentido da existência.

Para dar um exemplo, Lacan diz das esferas que a ciência afirma rodearem a terra. Embora não as enumere, sabemos que a atmosfera terrestre é composta por cinco camadas: troposfera, estratosfera, mesosfera, termosfera e exosfera. Essas camadas vão do nível do mar, a exosfera, à camada que antecede o espaço sideral (CAMADAS da atmosfera, s.n.). Tais divisões são colocadas por Lacan na ordem da nomenclatura. Elas são, pois, classificações estabelecidas pela Geociência, enquanto as latusas não pertencem às ciências naturais. Não se encontram no mesmo rol das camadas atmosféricas ou mesmo das ondas hertzianas. Lacan afirma que em relação a elas a fenomenologia da percepção nunca nos deu qualquer indicação (a não ser indiretamente, acrescentamos). Então, em qual lugar poderemos encontrá-las?

Lacan responde, mas o faz, a princípio, de forma negativa: "não o chamamos de noosfera" (Lacan, 1969-1970/1992, p.171). O lugar das latusas não é a noosfera. E o que vem a ser a noosfera? Esse é um termo empregado por Édouard le Roy (1931) para tentar resolver o problema que a existência do homem coloca para as ciências naturais. Para conseguir resolvê-lo, é preciso retornar, diz Le Roy, a uma noção introduzida em 1875 pelo geólogo austríaco Eduard Suess, qual seja, a biosfera. Nela se incluem todos os organismos que vivem no planeta, isto é, o conjunto dos seres vivos da Terra.

A biosfera pode ser considerada como a unidade real que possui a camada vivente que rodeia o mundo e funciona como um verdadeiro organismo de ordem superior. Essa noção foi proposta como homóloga à compreensão das grandes zonas telúricas da estrutura da Terra, cuja nomeação já existia em 1875 e que se constituiu para nomear suas partes, tais como a "litosfera" (o conjunto dos sólidos da Terra), a "hidrosfera" (o conjunto das águas da Terra), e a "atmosfera" (o conjunto das camadas de gases da Terra, acima citado), todas tomadas como realidades consistentes e positivas. É a elas que Le Roy (1931) acrescenta a Noosfera, dizendo que, se quisermos inserir o homem na história universal da vida sem mutilá-lo ou desorganizá-la, é necessário colocá-lo na Noosfera:

Acima da natureza inferior, numa situação onde ela a domine, mas que, todavia, não a desenraize; e isso retorna, de uma forma ou de outra, a imaginar, mais alta do que a biosfera animal, dando-lhe prosseguimento, uma esfera humana, a esfera da reflexão, da invenção consciente e livre, do pensamento propriamente dito: breve, a esfera do espírito ou Noosfera (Le Roy, 1931, p.46) ${ }^{1}$.

Para Le Roy (1931), com a humanidade aparece uma nova ordem de realidade que mantém uma relação estreita com o mundo dito inferior da vida, relação similar à que existe entre a vida e a matéria.

Como dito, Lacan (1969-1970/1992) não chamará de noosfera aquilo que, em sua concepção, é povoado por nós mesmos. Pouquíssimo interessado no tema, ele lança mão do conceito grego de verdade (aletheia) para lhe propor o nome de aletosfera, campo da presença humana, mesmo se estivéssemos em Marte ou a caminhar pela Lua.

Lacan evoca a aletosfera enquanto a esfera da verdade do humano, nas sendas abertas pela retomada crítica que Heidegger faz do significado de aletheia, mas ele o faz em um sentido muito próprio. Se a aletheia, para Heidegger, é "a verdade originária, é a verdade do Ser, a clareira (die Lichtung) que possibilita clarificar e desvelar a originariedade instauradora do comum-pertencer de Ser e homem" (Batista, 2005, § 1), para Lacan ela tem um sentido um pouco diferente; mas sem dúvida é nesse espaço de desvelamento que o homem se situa. É no sentido de "produzir efeitos de revelação" e "levantamentos do véu" - indicando assim a relação distorcida e complicada que o sujeito mantém com o saber -, que Jacques-Alain Miller, retomando o tema, afirma que a palavra verdade "dá continuidade ao ensino de Lacan, pois ela ali se encontra do início ao fim de sua obra" (Miller, 2008-2009/inédito, p.155).

Lacan torna a questão um tanto mais complexa ao afirmar que a verdade formalizada tem um status suficiente no nível onde ela opera, onde ela percebe dans l'operçoit (Lacan, 1969-1970/1991, p.187); mas, no nível do operado, do que passeia (ou deambula, como Roitman verte o "se promène)", a verdade, como diz Lacan, "não é de modo algum desvelada". [A voz humana] "não desvela de modo algum a sua verdade" (Lacan, 1969-1970/1992, p.171). Ainda em relação à aletosfera, Lacan observa que é necessário um tempo para que possamos perceber as coisas que a

\footnotetext{
Versão dos autores: "Si nous voulons parvenoir à insérer l'Homme dans une histoire universelle de la Vie, - sans mutiler celui-là, sens désorganiser celle-ci, - ce qu'il faut nécessairement, c'est le placer au-dessus de la nature infériere, dans une situation où il la dominemais, qui néanmoins, ne l'em déracine pás ; et cela revient, d'une façon ou de l'autre, à imaginer, plus haut que la biosphère animale et lui faissant suíte, une sphère humaine, la sphère de la réflexion, et de3 l'invention consciente et libre, de la pensée proprement dite : bref, la sphère de l'esprit ou Noosphère."
} 
povoam. Ele se pergunta: como nomeá-las? Para tal, será necessário, diz ele, introduzir outra palavra. Com a ajuda do aoristo ${ }^{2}$ do verbo do qual provém a aleteia, ele as chama latusas. Poderia também tê-las chamado de latousias. Tal denominação seria interessante por compor um termo no qual duas ideias poderiam se fundir, a de latusa e a de ousia ${ }^{3}$. Lacan, diz que a ousia "não é o Outro, nem é o ente, colocando-se entre os dois. Tampouco é o ser, mas chega muito perto disso" (Lacan, 1969-1970/1992, p.172).

O mundo está povoado de latusas, diz Lacan, que as define, mas, não sem antes fazer uma referência ao feminino.

Se no Seminário 22 (1975/inédito, p.11) ele dirá que a mulher é não toda (elle n'est pas tout), e, imediatamente antes, que Deus é a mulher tornada toda (rendue toute), no Seminário 17 ele diferencia a latusa do feminino. Na vertente da abertura ao gozo da mulher, mas não chegando tão longe quanto no Seminário 22, ainda no Seminário 17 , ele faz uma proposta ousada: "No que diz respeito à insubstância feminina, eu iria até a parusia" (Lacan, 1969-

2 “Aoristo é um tempo verbal existente nas línguas indoeuropeias, como o grego e o sânscrito. Aoristos, em grego, significa sem limite. Numa tradução mais livre, significa indefinido ou indeterminado. $\mathrm{O}$ Aoristo indica uma ação verbal ou acontecimento, sem definir absolutamente o seu tempo de duração, ou sem definir com precisão o tempo em que a ação ocorreu. É uma espécie de tempo passado indefinido, indeterminado. Nas línguas comuns e modernas, este tempo verbal não existe." Recuperado em 16 de setembro, 2009, de http://pt.wikipedia.org/wiki/Aoristo.

3 Ousia, substância, existência. Segundo Peters (s.n.), em Platão, tem várias significações. Por vezes, significa existência opondo-se à não existência, como quando aplicada à existência de coisas sensíveis (Platão, Teeteto, 186b), ou mesmo ligada à expressão "passar a existir" (gênesis eis ousia). Aristóteles distingue três tipos de ousia: (1) o sensível e eterno - como os corpos celestes; (2) o sensível e o perecível - como as substâncias, as plantas e os animais; e (3) o imutável - tal como o primeiro motor.

4 Parusia: transliterado do grego parousia, presença. Na religião cristã, retorno glorioso, ou segunda vinda de Jesus Cristo - enquanto presença -, no fim dos tempos, para presidir o Juízo final. Haveria alguma intenção de Lacan de apontar que o gozo feminino se abre na direção do escatológico, da última de todas as realidades? Na Lição de 16-12-1975, no Seminário 23, Lacan propõe o J ( $\square$ ), dizendo que o A barrado $(\square)$ quer dizer que "Não há Outro do Outro". Nada se opõe ao simbólico. Daí, não há Gozo do Outro. J ( $\square$ ), definido por ele como o gozo do Outro do Outro. Esse gozo não é possível, pela simples razão de que não existe (Lacan, 1975-1976/2007). Na lição seguinte, entretanto, e fazendo uma referência ao Juízo final, retoma: "Não há Outro do Outro", ajuntando-lhe: "para operar o Juízo final". Imediatamente, acrescenta: "Isso quer dizer
1970/1992, p.172). E no Seminário 20, na sua famosa tábua da sexuação, é como objeto $a$ que o homem a encontra $^{5}$ (Lacan, 1973/1975, p.73).

Finalmente, para definir a latusa, ele a relaciona aos objetos $a$, na mesma vertente de trabalho de seu seminário acima citado. Diz Lacan que esses objetos podem ser encontrados por toda a parte. Os que escutam a lição irão encontrá-los "ao sair, no pavimento de todas as esquinas, atrás de todas as vitrines e, mesmo, na proliferação dos objetos feitos para causar o desejo" (Lacan, 1969-1970/1992, p.172). Mas, não serão apenas os ouvintes de Lacan que irão encontrá-los, e sim todos nós, pois, "agora é a ciência que governa [o desejo]" (p.172). "Pensem neles - reitera - como latusas". É nesse sentido que a sua intervenção tem como finalidade provocar seus ouvintes ao ponto de se questionarem sobre suas relações com as latusas.

Curiosamente, ele termina a exposição dizendo que não só a palavra latusa (lathouse) rima com ventosa (ventouse) - o vento da voz humana - como é o analista quem ocupa esse lugar. Para estar nesta posição de latusa, conclui, é preciso ter discernido verdadeiramente - que é impossível. Portanto, enquanto psicanalistas, temos de nos safar como pudermos.

\section{A APOSTA DA PSICANÁlise FRENTE AO CAPITALISMO}

Representado por figuras cadavéricas consumidas na e pela paixão pelo consumo, o sujeito contemporâneo chega à clínica impulsionado pelo gozo e sobrecarregado pelo impasse de não poder abster-se dos objetos. Tarrab (2004) destaca que esse rechaço da falta do objeto leva ao apagamento da responsabilidade do sujeito, que fica à mercê dos imperativos contemporâneos de consumo inesgotável. Nesse circuito capitalista de preponderância do gozo sobre a palavra, cabe à clínica psicanalítica de orientação lacaniana fazer valer o inconsciente.

$\mathrm{O}$ significante estrutura o mundo do ser falante e sua articulação tem efeitos de sujeito, uma vez que a linguagem produz efeitos que escapam à apreensão

que há alguma coisa da qual não podemos gozar. Chamemos isso de o gozo de Deus, estando aí incluído o gozo sexual" (Lacan, 1975-1976/2007, p.59). Esta é uma das verdades primeiras que Lacan trouxe a seus alunos no início daquele ano.

5 Pois não há encontro possível do sujeito masculino, \$, com $\mathrm{L} \square$, uma mulher, que mantém suas ancoragens entre Phi maiúsculo e $S(\square)$ (Lacan, 1973/1975, p. 73). 
simbólica e que se relacionam à causa de desejo do sujeito. É o discurso do analista que promove o aparecimento da divisão subjetiva: o analista coloca-se na posição de causa de desejo, sem encarná-la, de modo a instituir o sujeito do inconsciente como aquele que poderá produzir algum saber, ainda que aos pedaços, pelas metades. Essa posição clínica permite que os produtos da cultura sejam retirados do lugar de objeto-tampão da falta estrutural, possibilitando ao sujeito lidar com as suas impossibilidades e sair do gozo autístico dos objetos de consumo.

Nesse sentido, a aposta da psicanálise lacaniana sustenta-se na imortalidade do desejo e na responsabilização do sujeito por suas escolhas. Lacan (1958/1998) localiza o desejo no intervalo entre a necessidade e a demanda. Embora a necessidade seja transmutada pela marca do significante em demanda, suas particularidades reaparecem para-além da demanda incondicional de presença e ausência do Outro, sem a possibilidade de serem abarcadas pelo significante. Ao mesmo tempo, a demanda pede desse Outro a equalização disso que escapa e que deixa restar um vazio de significação. É nessa hiância que o desejo se localiza e, desse modo, não se configura em apetite de satisfação nem em demanda de completude, mas refere-se ao próprio fenômeno de fenda do sujeito. Assim, fazer valer o desejo significa validar a castração e estimular a vida, pois é a presença de uma hiância que retira o sujeito do perigo de tentar funcionar na contramão do impossível da satisfação plena, liberando-o das estratégias insaciáveis da busca do gozo total.

Miller (2008-2009/inédito) retoma essa ideia lacaniana de que o desejo é, em rigor, inominável, e orienta que a clínica psicanalítica deve ser construída em uma via que abarque tanto os poderes do significante quanto a insistência do real. Segundo ele, o último ensino de Lacan considera que o gozo tem primazia sobre o significante, é impossível ele ser totalmente abarcado pelo simbólico e, por isso, pertence à dimensão do real. $\mathrm{O}$ inconsciente estruturado como uma linguagem, construído em análise e sob transferência, deve ser abordado como uma defesa contra esse gozo opaco à interpretação. A estrutura de linguagem não passa de elucubração sobre lalíngua, lugar do caos de elementos esparsos que habitam o inconsciente real, que não se deixa ordenar pelo simbólico.

$\mathrm{O}$ analista, incluindo essa perspectiva em sua condução clínica, deve ser menos aquele que demanda sentido e mais aquele que considera a insistência de um gozo provindo do real que não pode ser estruturado como uma linguagem. Deve-se levar em conta a satisfação extraída pelo falasser do seu modo de gozar particular, invariável e sem travessia, que carrega a função de apaziguar a urgência que leva o sujeito à análise.

É essa abertura ao impossível que possibilitará ao sujeito sair do aprisionamento capitalista de incitação à completude e de suas consequências mortíferas que o levam à ruína. Desse modo, a psicanálise lacaniana convida o sujeito a libertar-se dos universalismos de satisfação impostos pela cultura do consumo excessivo e lhe promete, não a completude, mas a abertura à particularidade de seu desejo.

\section{REFERÊNCIAS}

Alvarez, P. (2008). Antecedentes do discurso capitalista. @ gente: Revista Digital de Psicanálise, 5, 10-14. Recuperado em 21 de abril, 2009 ,

http://www.ebp.org.br/bahia/agente/agente_digital_05.pdf

Batista, J. B. (2005). A verdade do ser como Alétheia e errância. "Existência e Arte "- Revista Eletrônica do Grupo PET: Ciências Humanas, Estética e Artes da Universidade Federal de São João Del-Rei 1(1). Recuperado em 14 de setembro de 2009 em http://www.ufsj.edu.br/portal-epositorio/File/ existenciaearte/Edicoes/1_Edicao/A\%20verdade\%20do\%20ser $\% 20$ como\%20Aletheia\%20e\%20Errancia \%20Joao\%20Bosco\%20Batista.pdf

Camadas da atmosfera. s.n.t. Recuperado em 10 de setembro de 2009 em http://www.suapesquisa.com/geografia/ camadas_atmosfera.htm

Freud, S. (1996). O Mal-Estar na Civilização. (J. Salomão, Trad.). Edição Standard brasileira das Obras Psicológicas Completas de Sigmund Freud. (Vol.XXI, pp.73- 148). Rio de Janeiro: Imago. (Original publicado em 1930).

Lacan, J. (1958/1998). A significação do falo. (V. Ribeiro, Trad.). Em J. Lacan, Escritos (pp. 692-703). Rio de Janeiro: Jorge Zahar Ed. (Original publicado em 1966).

Lacan, J. (20-05-1970/1991). Les sillons de l'alèthposphère. Em J. Lacan, Le Séminaire.Livre 17: L'envers de la psychanalyse. (pp.175-190) Paris: Ed. du Seuil.

Lacan, J. (1969-1970/1992). O seminário. Livro 17: o avesso da psicanálise (A. Roitman, Trad.). Rio de Janeiro: Jorge Zahar Ed. (Original publicado em 1991).

Lacan, J. (1970/2003). Radiofonia. (V. Ribeiro, Trad.). Em J. Lacan, Outros escritos. (pp. 400-447) Rio de Janeiro: Jorge Zahar Ed. (Original publicado em 2001).

Lacan, J. (1972). Du discours psychanalytique. Conférence à l'université de Milan. Recuperado em 21 de abril de 2009 em http://pagespersoorange.fr/espace.freud/topos/psycha/psysem/italie.htm

Lacan, J. (1974/1993). Televisão. (A. Quinet, Trad.) Rio de Janeiro: Jorge Zahar Ed. (Original publicado em 1974).

Lacan, J. (1973/1975). Le Séminaire. Livre 20:Encore. Paris: Ed. du Seuil. (Original publicado em 1975).

Lacan, J. (1975). Le Séminaire. Livre 22: R.S.I. Inédito. (CD ROM). 
Lacan, J. (1975-1976/2007). O seminário. Livro 23: O sinthoma. (S. Laia, Trad.). Rio de Janeiro: Jorge Zahar Ed. (Original publicado em 1991).

Le Roy, É. (1931). La noosphére et l'hominization Em É. Le Roy, Les origines humaines et l'évolution de l'intelligence. (pp. 3757). Paris: Boivin.

Marx, K. (1857-1858). Elementos fundamentales para la crítica de la economia política. (J. Aricó, M. Murmis, P. Scaron, Trad.) México: Siglo Veintiuno Editores, 1989.

Masi, D. de. (1999). A sociedade pós-industrial. (J. Monteiro, Trad.) Em Masi, D. de.(Org.) A sociedade Pós-Industrial. São Paulo: Senac/SP.

Miller, J-A. (2008-2009/inédito). Coisas de Fineza em Psicanálise. (V. Ribeiro, Trad.). Documento de trabalho para os seminários de leitura da EBP. Inédito.

Peters, F. E. (s.n.). Termos filosóficos gregos, um léxico histórico. ( $2^{\mathrm{a}}$ ed.). (Barbosa, B. Trad.). Lisboa: Calouste Gulbenkian.
Platão. (1972). O Banquete. Em Platão. (J. Souza, Trad). Os pensadores. (v.3, pp. 9-59). (Trad. feita a partir dos textos de J. Burnet, de 1901 e de L. Robin, de 1929). São Paulo: Victor Civita.

Rabinovich, D. S. (2001). O Psicanalista entre o Mestre e o Pedagogo. Cadernos de Psicologia, UFMG-BH, 11, 9-28.

Souza, A. (2003). Duas exceções dos discursos radicais. Em A. Souza, Os discursos na Psicanálise. (pp.133-171). Rio de Janeiro: Companhia de Freud.

Tarrab, M. (2004). Mais-além do consumo. Parte I: a maldição do sexo e a época. Curinga, Belo Horizonte: EBP Seção Minas Gerais, 20, 55-69.

\section{Endereço para correspondência:}

Vanessa Leite Teixeira. Rua Ramalhete, 571/202, Serra, CEP 30210-500, Belo Horizonte-MG, Brasil.E-mail: vanessaleitet@gmail.com.
Recebido em 28/10/2009

Aceito em 09/06/2010 